\title{
Whey protein supplementation reducing fasting levels of anandamide and 2-AG without weight loss in pre-menopausal women with obesity on a weight-loss diet
}

Fatemeh Haidari ${ }^{1}$, Vahideh Aghamohammadi ${ }^{1,2^{*}}$, Majid Mohammadshahi ${ }^{1}$, Kambiz Ahmadi-Angali ${ }^{3}$ and Mohammad Asghari-Jafarabadi ${ }^{4}$

\begin{abstract}
Background: Despite the importance of dairy proteins in modifying of metabolic abnormalities, no attention has been given to their effects on endocannabinoids.

Methods: A total number of 60 obese women were recruited in a 2-month randomized clinical trial. Following random allocation, they were assigned to one of the two groups: control $(n=30)$ and intervention $(n=30)$. Then, all the subjects followed a hypocaloric diet of $800 \mathrm{kcal}$ below estimated energy needs. The intervention group received isocaloric weight-loss diet and whey protein powders (30 g/day). Baseline and 2-month fasting anthropometric, blood glucose, serum insulin, insulin resistance, lipid profile, AEA, and 2-AG were measured.

Results: The study groups were homogenous in terms of baseline characteristics ( $p>0.05)$ except for MUFA intake $(p=0.021)$. There were no significant differences in energy and macronutrient intakes in the intervention group compared to the control group at the end of the study $(p>0.05)$. The results of the ANCOVA did not show significant reductions in body weight and BMI of the intervention group compared to the control group $(p>0.05)$; however, WC, body fat, FBS, AEA, 2-AG, total cholesterol, and triglyceride decreased and HDL-c significantly increased in the intervention group compared to the control group $(p<0.05)$.
\end{abstract}

Conclusions: In this study, the effects of simultaneous weight-loss diet and whey protein supplementation on the reduction of endocannabinoids were determined.

Trial registration: Iranian Registry of Clinical Trials IRCT2017021410181N8. Registered on March 2017.

Keywords: Endocannabinoids, Hypocaloric diet, Obesity, Weight loss, Whey protein

\footnotetext{
* Correspondence: v_agamohammadi@yahoo.com

'Department of Nutrition, Nutrition and Metabolic Research Center, Faculty of Paramedical Sciences, Ahvaz Jundishapur University of Medical Sciences, Golestan Street, Ahvaz, Iran

${ }^{2}$ Department of Nutrition, Khalkhal University of Medical Sciences, Khalkhal, Iran

Full list of author information is available at the end of the article
}

(c) The Author(s). 2020 Open Access This article is licensed under a Creative Commons Attribution 4.0 International License, which permits use, sharing, adaptation, distribution and reproduction in any medium or format, as long as you give appropriate credit to the original author(s) and the source, provide a link to the Creative Commons licence, and indicate if changes were made. The images or other third party material in this article are included in the article's Creative Commons licence, unless indicated otherwise in a credit line to the material. If material is not included in the article's Creative Commons licence and your intended use is not permitted by statutory regulation or exceeds the permitted use, you will need to obtain permission directly from the copyright holder. To view a copy of this licence, visit http://creativecommons.org/licenses/by/4.0/. The Creative Commons Public Domain Dedication waiver (http://creativecommons.org/publicdomain/zero/1.0/) applies to the data made available in this article, unless otherwise stated in a credit line to the data. 


\section{Background}

Obesity refers to excessive accumulation of fat in the body which can lead to an increase in disability and mortality by predisposing people to other diseases. $\mathrm{Ng}$ et al. estimated that in 2013, more than 2 billion people in the world were overweight or obese and about 671 million of them were obese [1]. In Iran, obesity and overweight in recent years are on a growth, and according to a review study in Iran, $21 \%$ of people over 18 are obese [2]. Women are also at greater risk for obesity, so that $22.5 \%$ of women are obese versus $10.5 \%$ of men [3]. Moreover, obesity and overweight are associated with diabetes, myocardial infarction, high blood pressure, dyslipidemia, sleep apnea, gallbladder disease, coronary artery disease, gout, cancer and asthma, mental disorders, and depression $[4,5]$.

Recently, it has been discovered that ECS (endocannabinoid system) plays a critical role in obesity, high fasting glucose and insulin levels, and insulin resistance and dyslipidemia [6, 7]. The ECS is important in the control and regulation of body weight, since stimulation of CB1 (cannabinoid receptor 1) by anandamide (AEA) and 2arachidonoylglyceride (2-AG) is associated with increased appetite, higher food intakes, weight gain, and obesity [8]. AEA and 2-AG also play an important role in regulating energy hemostasis, metabolism, and body composition. Obese individuals have higher plasma levels of AEA and 2-AG compared to non-obese controls of both genders $[7,9]$. However, plasma endocannabinoids (ECs) are higher in obese women compared to obese men $[10,11]$. Sipe et al. verified that circulating ECs could predict obesity risks and proposed targeting ECs as a novel strategy for treating obesity [12].

Whey protein is considered as one of the highest-quality proteins given its amino acid content (high essential and branched-chain amino acid content) and rapid digestibility. Amino acids and peptides from whey protein may also reduce the food intake via release of gut hormones (CCK and GLP-1) [13], and reduction of neuropeptide orexigenic (NPY) and increase of neuropeptide anorexigenic (POMC) in the hypothalamus [14]. The effect of whey on reducing AEA and 2-AG endocannabinoids may be due to the effect on digestive hormones that have a gutbrainstem relationship. These hormones probably block the depolarization-induced suppression by inhibiting voltage-gated calcium channels, resulting in decreased calcium influx and consequently lowered ECB synthesis [15, 16]. $C B 1$ is present in neurons of the enteric nervous system and sensory terminals of vagal and spinal neurons in the gastrointestinal tract. ECS has been found to regulate food intake through the vagus nerve, which connects the medulla and brainstem nuclei associated with satiety with the gastrointestinal tract to monitor the status of digestive processes [6].
Given the putative role of whey protein, plasma EC association with visceral obesity and metabolic profile, and due to the fact that the effect of whey protein on EC concentration is not clear [17], we aimed to evaluate the effects of whey protein supplementation on fasting levels of endocannabinoids, lipid profile, glucose, insulin, HOMA-IR, and anthropometric indices in obese women on a weight-loss diet.

\section{Methods}

\section{Study design and intervention}

The present study was a randomized clinical trial determining the effects of whey supplementation on fasting levels of ECs, lipid profile, glucose, insulin, HOMA-IR, and anthropometric indices in 60 non-menopausal obese women on a weight-loss diet. This research study was registered in the Iranian Registry of Clinical Trials (IRCT registration number: IRCT2017021410181N8).

By referring to dietary clinics in the city of Ahvaz, subjects meeting the inclusion criteria were recruited in this trial after obtaining their written consent (May 2017 to July 2017). The inclusion criteria in this study were as follows: age of 18 years and older, BMI range of 30 to $40 \mathrm{~kg} / \mathrm{m}^{2}$, absence of menopause, lactation, pregnancy, and food allergies; having no cancer, as well as hepatic, renal, thyroid, and gastrointestinal disorders; no surgery for weight loss; no weight loss over the past 6 months; and taking no herbs and drugs reducing appetite and weight as well as vitamin-mineral supplements.

The sample size was considered according to the changes in AEA level, in response to weight loss, based on the study carried out by Mallipedhi et al., and then, 30 subjects were recruited for each group $(\alpha=0.05, \beta=$ $0.2, \mathrm{~S} 1=0.042, \mathrm{~S} 2=0.049, \mu 1=0.297, \mu 2=0.209) \quad[18]$. The subjects were randomly stratified according to age and BMI using permuted block randomization procedure by Random Allocation Software (RAS), and assigned to one of the two study groups: control (standard weight-loss group, $n=30$ ) and intervention (whey supplementation weight-loss group, $n=30$ ).

The demographic and physical activity information was also collected through a questionnaire. In order to assess the physical activity of individuals, at the baseline and the end of the study, the International Physical Activity Questionnaire (IPAQ) [19] was used via interviewing and the results were expressed as "high," "moderate," and "low" activity.

At the baseline, the 4th week, and the end of study, body weight and height were measured using a seca scale with an accuracy of $100 \mathrm{~g}$ and a seca stadiometer with an accuracy of $0.5 \mathrm{~cm}$, respectively, and then, BMI was calculated as body weight $(\mathrm{kg})$ divided by the square of height $(\mathrm{m})$. At the baseline and at the end of study, waist circumference (WC) was measured in standing 
position using a tape with an accuracy of $1.0 \mathrm{~cm}$ at above the iliac crest, just below the lowest rib margin and at the end of normal expiration. TANITA BC-418 body composition analyzer was also employed to calculate total body fat and fat-free mass percentage.

Energy requirements were then estimated by the Mifflin Jeor St equation [20], and all subjects followed a hypocaloric diet of $800 \mathrm{kcal}$ below estimated energy needs, which was designed by a trained dietitian in order to reach weight loss of more than $10 \%$. In the control group, the percentage of macronutrients was determined by $55 \%, 30 \%$, and $15 \%$ for carbohydrate, fat, and protein, respectively. The intervention group also received isocaloric weight-loss diet and whey protein powders. Each intervention group subject consumed $30-\mathrm{g}$ whey protein powders daily in the evenings lasting 2 months. The supplements were provided in a sachet form (each sachet containing $30 \mathrm{~g}$ of whey protein). Each sachet contained $116 \mathrm{kcal}, 0.5 \mathrm{~g}$ of lipid, $0.4 \mathrm{~g}$ of carbohydrate, and $27.5 \mathrm{~g}$ of protein. Whey protein powders were supplied by Karen Pharma \& Food Supplement Co., Tehran, Iran. Regarding the calorie of each whey sachet $(116 \mathrm{kcal})$, 912 cal below estimated energy needs was considered for the intervention group. To ensure that the intervention group subjects could regularly consume the supplement, they were contacted every 3 days by a dietitian, or if it was not possible to call them, they were tracked through SMS. Dietary intake was also evaluated by 3-day 24-h recall questionnaires ( 2 week days and 1 weekend day) at the baseline and at the end of the study. Total energy and macronutrient intake were then calculated using Nut IV (the Hearst Corporation, San Bruno, CA). For the purpose of biochemical evaluation, the 10-cc fasting blood samples were collected at the beginning and at the end of the study. The CONSORT flow diagram of this trial is shown in Fig. 1.

\section{Biochemical analyses}

To determine the plasma AEA and 2-AG, the blood in EDTA-coated tubes was centrifuged at $1500 g$ at $4{ }^{\circ} \mathrm{C}$ for $15 \mathrm{~min}$ and was then stored at $-80^{\circ} \mathrm{C}$. ELISA kits (HANGZHOU EASTBIOPHARM CO., LTD.) were also used to measure levels of endocannabinoids. Blood glucose, total cholesterol, LDL-c, HDL-c, and triglyceride were also determined by enzymatic method with kits from Pars-Azmoon (Tehran, Iran). Insulin levels were similarly measured by chemiluminescent immunoassay. Homeostasis model assessment-insulin resistance

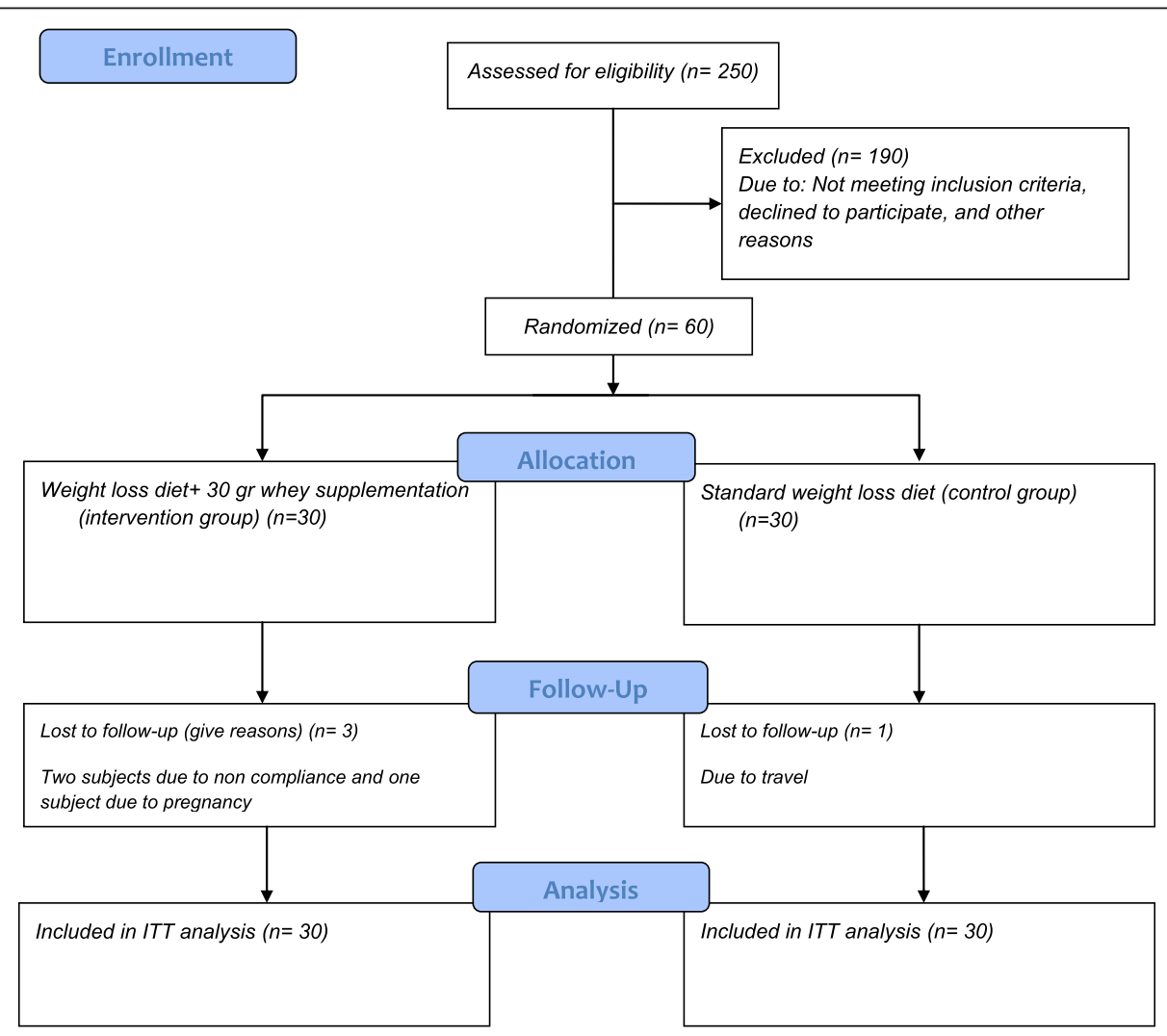

Fig. 1 CONSORT flow diagram. We conducted a 2-month open-label, parallel-group, randomized controlled trial to determine the effect of whey protein supplementation on levels of endocannabinoids, glycemic and lipid profile, and body composition in 60 pre-menopausal obese women on a weight-loss diet 
(HOMA-IR) was calculated by the following formula: fasting glucose $(\mathrm{mg} / \mathrm{dl}) \times$ fasting insulin $(\mu \mathrm{u} / \mathrm{ml}) / 405$.

\section{Statistical analyses and covariates}

All statistical analyses were performed using IBM SPSS Statistics software (version 24) (IBM SPSS Statistics, Armonk, USA). The normality of the variables was confirmed using the Kolmogorov-Smirnov test. To compare the categorical data between treatment groups at the baseline, chi-square test was employed. Independent sample $t$ test and paired sample $t$ test were applied to compare parametric continuous data between and within the groups, respectively. The Mann-Whitney $U$ test and Wilcoxon signed-rank test were also applied to test the differences in asymmetric variables between and within the groups, respectively. To control the confounding variables, analysis of covariance (ANCOVA) test was used in order to determine the differences between the two groups at the post-intervention stage, while adjusting for changes in intake of energy, percentage of carbohydrate, protein, total fat, saturated fatty acid (SFA), monounsaturated fatty acid (MUFA), polyunsaturated fatty acid (PUFA), and other fat and baseline values.

A $p$ value less than 0.05 was considered to be statistically significant. All the categorical and numeric variables were presented as number (percentage) and mean (standard deviation), respectively.

\section{Results}

Three subjects in the intervention group (two subjects due to non-compliance and one subject following pregnancy) and one participant in the control group due to travel were lost to follow-up. All the analyses were performed using the intention-to-treat principle (control group, $n=30$, and intervention group, $n=30$ ). The study groups were homogenous in terms of the baseline physical activity levels, demographic characteristics, anthropometric feature, and dietary intake, except for the MUFA intake $(p>0.05)$ (Table 1). No significant changes were also seen in subjects' physical activity levels during the trial, within or between the two groups $(p>0.05)$.

\section{Dietary intake}

The mean scores of subjects' dietary intakes are illustrated in Table 2. There were no significant differences in energy and macronutrient intakes $(p>0.05)$, except for the MUFA intake $(p=0.027)$, among the study groups, at the baseline and the end of the study. In the intervention group, compared to the baseline, energy and carbohydrate percentage intakes decreased by $955.26 \mathrm{kcal}$ and $11.67 \%$, respectively. The protein and fat percentage intake increased by $2.53 \%$ and $9.53 \%$, respectively. In the control group, compared to the baseline, energy and carbohydrate percentage intakes decreased by $967.05 \mathrm{kcal}$ and $8.96 \%$, respectively, and the protein and fat percentage intake increased by $1.13 \%$ and $7.83 \%$, respectively.

Table 1 Baseline characteristics of study participants

\begin{tabular}{|c|c|c|c|c|}
\hline Variables & All subjects & Intervention group $(n=30)$ & Control group $(n=30)$ & $p$ value $^{c}$ \\
\hline Age (years) ${ }^{a}$ & $31.61(5.73)$ & $31(6.28)$ & $32.23(5.17)$ & 0.410 \\
\hline Weight $(\mathrm{kg})^{\mathrm{a}}$ & $89.39(9.64)$ & $90.03(10.51)$ & $88.74(8.81)$ & 0.442 \\
\hline Height $(\mathrm{cm})^{\mathrm{a}}$ & $163.34(3.57)$ & $163.7(3.67)$ & $162.98(3.49)$ & 0.610 \\
\hline $\mathrm{BMI}\left(\mathrm{kg} / \mathrm{m}^{2}\right)^{\mathrm{a}}$ & $33.45(2.89)$ & $33.54(3.17)$ & $33.36(2.63)$ & 0.820 \\
\hline$W C(\mathrm{~cm})^{\mathrm{a}}$ & $99.37(8.76)$ & $99.63(8.78)$ & $99.11(8.88)$ & 0.822 \\
\hline Married status ${ }^{b}$ & & & & 0.779 \\
\hline Married & $42(70 \%)$ & $20(66.66 \%)$ & $22(73.33 \%)$ & \\
\hline Unmarried & $18(30 \%)$ & $10(33.33 \%)$ & $8(26.66 \%)$ & \\
\hline Job status ${ }^{b}$ & & & & 0.943 \\
\hline Employees & $11(18.3 \%)$ & $6(20 \%)$ & $5(16.66 \%)$ & \\
\hline Non-administrative employees & $10(16.7)$ & $5(16.66 \%)$ & $5(16.66 \%)$ & \\
\hline Housewife & $39(65)$ & $19(63.32 \%)$ & $20(66.66 \%)$ & \\
\hline Physical activity ${ }^{b}$ & & & & 1.000 \\
\hline Low & & $24(80 \%)$ & $24(80 \%)$ & \\
\hline Moderate & & $6(20 \%)$ & $6(20 \%)$ & \\
\hline High & & $0(0 \%)$ & $0(0 \%)$ & \\
\hline
\end{tabular}

$B M I$ body mass index, WC waist circumference

${ }^{a}$ Mean (SD)

${ }^{\mathrm{b}}$ Number (\%)

'Independent $t$ test for numeric variables and Pearson's chi-square test for categorical variables 
Table 2 Daily dietary intakes of the study participants at baseline and 2 months after the intervention

\begin{tabular}{|c|c|c|c|c|}
\hline \multicolumn{2}{|l|}{ Variable } & \multirow{2}{*}{$\begin{array}{l}\text { Intervention group }(\boldsymbol{n}=\mathbf{3 0}) \\
2584.61(208.08)^{\mathrm{a}}\end{array}$} & \multirow{2}{*}{$\begin{array}{l}\text { Control group }(\boldsymbol{n}=\mathbf{3 0}) \\
2552.04(206.68)\end{array}$} & \multirow{2}{*}{$\begin{array}{l}p \text { value }^{\text {b, }} \\
0.545^{\text {b }}\end{array}$} \\
\hline Energy (kcal/day) & Before & & & \\
\hline & After & 1629.35 (194.78) & $1584.99(203.23)$ & $0.392^{c}$ \\
\hline & $p^{d}$ & $<0.001$ & $<0.001$ & \\
\hline \multirow[t]{3}{*}{ Carbohydrate (\% energy) } & Before & $66.73(7.58)$ & $64.13(8.74)$ & $0.224^{b}$ \\
\hline & After & $55.04(0.99)$ & $55.17(0.95)$ & $0.612^{c}$ \\
\hline & $p^{d}$ & $<0.001$ & $<0.001$ & \\
\hline \multirow[t]{3}{*}{ Protein (\% energy) } & Before & $12.66(2.97)$ & $13.83(2.50)$ & $0.116^{b}$ \\
\hline & After & $14.82(0.53)$ & $14.96(0.61)$ & $0.350^{c}$ \\
\hline & $p^{d}$ & 0.001 & 0.023 & \\
\hline \multirow[t]{3}{*}{ Total fat (\% energy) } & Before & $20.16(6.3)$ & $22.03(8.74)$ & $0.465^{b}$ \\
\hline & After & $30.13(1.10)$ & $29.86(1.13)$ & $0.359^{c}$ \\
\hline & $p^{d}$ & $<0.001$ & $<0.001$ & \\
\hline \multirow[t]{3}{*}{ SFA (g) } & Before & $18.12(7.09)$ & $19.39(9.99)$ & $0.573^{b}$ \\
\hline & After & $13.61(4.30)$ & $14.26(6.31)$ & $0.646^{c}$ \\
\hline & $p^{d}$ & $<0.001$ & $<0.001$ & \\
\hline \multirow[t]{3}{*}{ MUFA (g) } & Before & $13.41(5.94)$ & $18.61(1.96)$ & $0.027^{b}$ \\
\hline & After & $7.44(3.66)$ & $10.25(7.16)$ & $0.062^{c}$ \\
\hline & $p^{d}$ & $<0.001$ & $<0.001$ & \\
\hline \multirow[t]{3}{*}{ PUFA (g) } & Before & $12.28(8.95)$ & $12.99(10.03)$ & $0.771^{b}$ \\
\hline & After & $25.00(10.91)$ & $21.84(10.24)$ & $0.249^{c}$ \\
\hline & $p^{d}$ & $<0.001$ & 0.013 & \\
\hline \multirow[t]{3}{*}{ Other fat (g) } & Before & $15.73(11.90)$ & $12.76(4.70)$ & $0.208^{b}$ \\
\hline & After & $8.46(7.42)$ & $6.31(2.97)$ & $0.149^{c}$ \\
\hline & $p^{d}$ & $<0.001$ & $<0.001$ & \\
\hline
\end{tabular}

MD mean difference, $C$ confidence interval, SFA saturated fatty acid, MUFA monounsaturated fatty acid, PUFA polyunsaturated fatty acid ${ }^{a}$ Mean (SD). $p$ values of statistical significance $(p<0.05)$ are presented in bold

${ }^{\mathrm{b}}$ Independent $t$ test for intake of energy, carbohydrate, protein, and total fat and Mann-Whitney $U$ for SFA, MUFA, PUFA, and other fat

${ }^{C}$ Analysis of covariance (adjusted for changes in intake of energy, percent of carbohydrate, protein, total fat, SFA, MUFA, PUFA, and other fat and baseline values)

${ }^{\mathrm{d}}$ Paired $t$ test intake of energy, carbohydrate, protein, and total fat and Wilcoxon for SFA, MUFA, PUFA, and other fat

\section{Anthropometric measurements}

As shown in Table 3, there were no significant differences in anthropometric measurements between the study groups at the baseline $(p>0.05)$. At the end of the study, all the anthropometric indices significantly reduced in both groups $(p<0$. 001). The results of ANCOVA did not show significant reductions in body weight and BMI in the intervention group compared to those in the control group $(p>0.05)$, but WC and body fat were decreased significantly in the intervention group compared to those in the control group. Regarding the fat-free mass, it decreased significantly in the control group ( -2.02 , CI -2.36 to -1.69$)$ compared to those in the intervention group $(-1.00, \mathrm{CI}-1.38$ to -0.63$)$.

\section{Biochemical parameters}

No significant between-group differences were found in the biochemical values, at the baseline $(p>0.05)$. At the end of the study, the AEA and 2-AG levels significantly decreased in the whey intervention group $(-6.02 \mathrm{ng} / \mathrm{ml}$ (CI -8.75 to -3.28$),<0.001 ;-8.28 \mathrm{ng} / \mathrm{ml}$ (CI -12.00 to $-4.54),<0.001$, respectively). The mean difference in the AEA and 2-AG levels between the two groups after the intervention was significant $(-1.76$ (CI -4.42 to 0.90$), p$ value $<0.001 ;-2.52$ ( $\mathrm{CI}-6.71$ to 1.67 ), $p$ value $<0.001$, respectively) (tested by ANCOVA after adjusting for covariates).

As shown in Table 4, total cholesterol, LDL-c, and triglyceride levels significantly reduced and HDL-c levels increased in the intervention group compared to baseline $(p<0.05)$, but changes in these variables were not significant in the control group $(p>0.05)$. Fasting insulin levels and HOMA-IR also reduced significantly in both groups at the end of the study $(p<0.05)$. In the intervention group, levels of fasting glucose, total cholesterol, and triglyceride significantly decreased $(p=0.044, p=$ $0.013, p=0.03$, respectively), and HDL-c $(p=0.006)$ significantly increased compared to the control group 
Table 3 Anthropometric indices of study groups at baseline and end of the intervention

\begin{tabular}{|c|c|c|c|c|}
\hline Variable & & Intervention group $(n=30)$ & Control group $(n=30)$ & $p$ value $^{\mathrm{b}, \mathrm{c}}$ \\
\hline \multirow[t]{3}{*}{ Body weight (kg) } & Before & $90.03(10.51)^{\mathrm{a}}$ & $88.74(8.81)$ & $610^{\mathrm{b}}$ \\
\hline & After & $86.22(9.27)$ & $85.55(8.83)$ & $0.645^{c}$ \\
\hline & $p^{d}$ & $<0.001$ & $<0.001$ & \\
\hline \multirow[t]{3}{*}{ BMI $\left(k g / m^{2}\right)$} & Before & $33.54(3.17)$ & $33.36(2.63)$ & $0.820^{b}$ \\
\hline & After & $32.14(2.9)$ & $32.16(2.61)$ & $0.611^{c}$ \\
\hline & $p^{d}$ & $<0.001$ & $<0.001$ & \\
\hline \multirow[t]{3}{*}{ WC (cm) } & Before & $99.63(8.78)$ & $99.11(8.88)$ & $0.822^{b}$ \\
\hline & After & $95.60(8.48)$ & $97.52(8.80)$ & $<0.001^{c}$ \\
\hline & $p^{d}$ & $<0.001$ & $<0.001$ & \\
\hline \multirow[t]{3}{*}{ Body fat (kg) } & Before & $39.16(7.12)$ & $38.35(6.26)$ & $0.640^{b}$ \\
\hline & After & $34.81(5.98)$ & $35.38(5.89)$ & $0<001^{c}$ \\
\hline & $p^{\mathrm{d}}$ & $<0.001$ & $<0.001$ & \\
\hline \multirow[t]{3}{*}{ Body fat-free mass (\%) } & Before & $22.08(2.24)$ & $22.30(1.86)$ & $0.697^{b}$ \\
\hline & After & $21.07(1.90)$ & $20.25(1.82)$ & $0.002^{c}$ \\
\hline & $p^{d}$ & $<0.001$ & $<0.001$ & \\
\hline
\end{tabular}

$M D$ mean difference, $C l$ confidence interval, $B M I$ body mass index, $W C$ waist circumference

${ }^{a}$ Mean (SD). $p$ values of statistical significance $(p<0.05)$ are presented in bold

Independent $t$ test

'Analysis of covariance (adjusted for changes in intake of energy, percent of carbohydrate, protein, total fat, SFA, MUFA, PUFA, and other fat and baseline values)

${ }^{\mathrm{d}}$ Paired $t$ test

(tested by ANCOVA after adjusting for covariates) (Table 4).

\section{Discussion}

The present trial evaluated the effect of whey protein supplementation on fasting levels of endocannabinoids, lipid profile, glucose, insulin, HOMA-IR, and anthropometric indices in obese women on a weight-loss diet. Accordingly, the whey supplementation along with weight-loss diet induced a significant decrease of AEA and 2-AG levels in the intervention group compared to the control group.

The regulation of ECS is impaired in obesity, and increased levels of endocannabinoids in obesity lead to increased fatty cell size, fatty tissue macrophage content, inflammatory processes, and metabolic changes associated with obesity [21].

In human studies, the impact of weight loss from hypocaloric diets on ECs is conflicting. In this respect, Engeli et al. quantified serum AEA, 2-AG levels, CB1, and FAAH gene expression in obese postmenopausal women and observed no changes after $5 \%$ weight loss from caloric restriction [22]. Also, it was reported that at least $10 \%$ weight loss was required to be achieved to influence weight loss on circulating AEA and 2-AG levels $[22,23]$. In contrast, one of the important findings of the present study was that supplementation of whey protein along with weight-loss diet could reduce AEA and 2-AG without significant drop in weight and BMI compared with the control group which suggested that whey protein could improve obesity biomarkers through the mechanisms other than weight loss. In this study, weight loss for both groups was less than $5 \%$. It should be noted that the study population and the weight-loss method were different from those in other investigations [7, 18, 22, 23].

Recent studies have demonstrated the significant role of whey protein supplementation in glycemia control, possibly through the stimulation of incretin hormones, which increase fasting and postprandial insulin release and improve insulin sensitivity [24]. In the other studies, consistent with the present study, whey protein could decrease the blood glucose, but these studies considered non-obese subjects (with BMI 26.2 to 28.2) [25, 26]. In a study by Sukkar et al. after 10 days of protein-sparing modified fast followed by 20 days of a low-calorie diet, in patients with morbid obesity, fasting glucose, insulin, and HOMA-IR were significantly reduced [27]. High BMI could also have a negative effect on the response of incretins to whey supplementation, and it is unclear how diabetes and obesity reduce the response of incretins to whey supplementation. It has been shown that in obese women with metabolic syndrome, insulin resistance can have a significant positive correlation with plasma levels of branched-chain amino acids, but weight loss could eliminate this correlation [28]. Almario et al. in a study assessing the effect of whey on glycemic indices in diabetic patients suggested that lower BMI, normal triglycerides, and low serum GLP-1 were glucose-response positive predictive variables in response to supplementation of whey protein [29]. The bioactive peptides were identified in whey 
Table 4 Biochemical parameter values of the study groups at baseline and at the end of the intervention

\begin{tabular}{|c|c|c|c|c|}
\hline \multicolumn{2}{|l|}{ Variable } & \multirow{2}{*}{$\frac{\text { Intervention group }(\boldsymbol{n}=\mathbf{3 0})}{11.50(8.83)^{a}}$} & \multirow{2}{*}{$\begin{array}{l}\text { Control group }(\boldsymbol{n}=\mathbf{3 0}) \\
8.07(6.21)\end{array}$} & \multirow{2}{*}{$\begin{array}{l}p \text { value }^{\text {b, }} \\
0.090^{\mathrm{b}}\end{array}$} \\
\hline AEA (ng/ml) & Before & & & \\
\hline & After & $5.49(4.23)$ & $7.25(5.90)$ & $<0.001^{c}$ \\
\hline & $p^{d}$ & $<0.001$ & 0.006 & \\
\hline \multirow[t]{3}{*}{ 2-AG (ng/ml) } & Before & 16.39 (13.36) & $11.92(8.99)$ & $0.183^{b}$ \\
\hline & After & $8.11(7.72)$ & $10.64(8.38)$ & $0.001^{c}$ \\
\hline & $p^{d}$ & $<0.001$ & 0.012 & \\
\hline \multirow[t]{3}{*}{$\mathrm{TC}(\mathrm{mg} / \mathrm{dl})$} & Before & $141.51(20.14)$ & $148.53(26.37)$ & $0.257^{b}$ \\
\hline & After & $129.63(19.72)$ & $146.79(24.60)$ & $0.013^{c}$ \\
\hline & $p^{\mathrm{d}}$ & 0.003 & 0.707 & \\
\hline \multirow[t]{3}{*}{ LDL-C (mg/dl) } & Before & 75.3 (15.98) & $75.06(12.53)$ & $0.950^{b}$ \\
\hline & After & $68.46(9.05)$ & $72.51(11.07)$ & $0.095^{c}$ \\
\hline & $p^{d}$ & 0.014 & 0.258 & \\
\hline \multirow[t]{3}{*}{ HDL-C (mg/dl) } & Before & $40.33(4.03)$ & $41.43(5.36)$ & $0.373 b$ \\
\hline & After & $44.21(4.71)$ & $41.41(5.60)$ & $0.006^{c}$ \\
\hline & $p^{d}$ & $<0.001$ & 0.983 & \\
\hline \multirow[t]{3}{*}{$\mathrm{TG}(\mathrm{mg} / \mathrm{dl})$} & Before & $132.03(34.33)$ & $136.96(50.83)$ & $0.661^{b}$ \\
\hline & After & $108.49(25.18)$ & 130.17 (49.98) & $0.030^{c}$ \\
\hline & $p^{d}$ & $<0.001$ & 0.346 & \\
\hline \multirow[t]{3}{*}{ FBS (mg/dl) } & Before & $86.66(9.89)$ & $81.76(10.09)$ & $0.062^{b}$ \\
\hline & After & $79.37(8.31)$ & $79.39(8.08)$ & $0.044^{c}$ \\
\hline & $p^{d}$ & $<0.001$ & 0.035 & \\
\hline \multirow[t]{3}{*}{ Insulin $(\mu \mathrm{IU} / \mathrm{ml})$} & Before & $9.30(5.10)$ & $7.62(5.16)$ & $0.220^{b}$ \\
\hline & After & $5.65(2.33)$ & $5.91(3.20)$ & $0.124^{c}$ \\
\hline & $p^{d}$ & $<0.001$ & 0.018 & \\
\hline \multirow[t]{3}{*}{ HOMA-IR } & Before & $1.96(1.00)$ & $1.60(1.24)$ & $0.213^{b}$ \\
\hline & After & $1.11(0.49)$ & $1.17(0.69)$ & $0.070^{c}$ \\
\hline & $p^{d}$ & $<0.001$ & 0.010 & \\
\hline
\end{tabular}

$M D$ mean difference, $C$ c confidence interval, $A E A$ anandamide (AEA), 2-AG 2-arachidonoylglyceride, $T C$ total cholesterol, $L D L-C$ low-density lipoprotein cholesterol, $H D L-C$ high-density lipoprotein cholesterol, TG triglycerides, FBS fasting blood sugar, HOMA-IR homeostasis model assessment for insulin resistance ${ }^{a}$ Mean (SD). $p$ values of statistical significance $(p<0.05)$ are presented in bold

${ }^{\mathrm{b}}$ Independent $t$ test for TC, HDL-C, LDL-C, TG, and FBS and Mann-Whitney $U$ for AEA, 2-AG, insulin, and HOMA-IR

'Analysis of covariance (adjusted for changes in intake of energy, percent of carbohydrate, protein, total fat, SFA, MUFA, PUFA, and other fat and baseline values)

${ }^{d}$ Paired $t$ test for TC, HDL-C, LDL-C, TG, and FBS and Wilcoxon for AEA, 2-AG, insulin, and HOMA-IR

protein which might also serve as endogenous inhibitors of dipeptidyl peptidase-4 (DPP-4) in the proximal gut, and prevent incretin degradation $[14,24]$.

In this study, after whey isolate supplementation along with weight-loss diet, significant decrease of total cholesterol and triglyceride levels and increase of HDL-C levels were observed. One of the main components of whey is $\beta$ lactoglobulin $(45-57 \%)$ that has higher content of branched-chain amino acids $(\sim 25.1 \%)$, captures hydrophobic molecules, and then contributes to the reduction of intestinal absorption of lipids [14]. Whey protein supplementation could also improve lipid profiles and metabolic syndromes by increasing the expression of cholesterol carriers and decreasing cholesterol accumulation and expression of lipogenic lipid enzymes [30]. Whey protein consists of angiotensin converting enzyme (ACE) inhibitors. Angiotensin 2 causes an increased expression of the fatty acid synthase enzyme; therefore, the inhibition of ACE by whey protein results in decreased endogenous production of lipids [31]. Pal et al. demonstrated that 12 weeks of supplementation with whey proteins in comparison to casein and glucose (control) supplementation could improve fasting lipids and insulin levels in overweight and obese individuals [32]. Hong et al. also examined antiobesity effects of whey in rats with high-fat diet and eventually observed lower levels of total cholesterol, triglyceride, and LDL-c in the whey-recipient group compared to other study groups [33]. Moreover, Sukkar et al. after 10 days of whey protein-sparing modified fasting (Promofast) observed a significant improvement in lipid profile [27]. 
At the end of the study, all the anthropometric indices significantly reduced in both groups. The results of ANCOVA did not show significant reductions in body weight and BMI in the intervention group compared to those in the control group. The anorexic effect of whey protein is observed prevalently when whey protein is assumed on fasting in rats and humans [13, 34, 35] because whey protein is a fast protein [13] but only in fasting conditions. Moreover, Soop et al. showed if whey protein is mixed in a meal with casein, casein exhibits a more sustained effect on plasma amino acid levels and muscle protein accretion compared with WP and therefore cannot inhibit appetite [36]. So, the scarce weight effect in the present study could be explained that the whey supplementation was not targeted to reduce appetite but only to verify the efficacy of WP on endocannabinoids.

According to the findings of this study, a supplement of $30 \mathrm{~g}$ of protein for 2 months in non-menopausal women under a weight-loss diet resulted in a significant reduction in body fat mass and waist circumference, as well as a lower loss mass muscle compared to the control group. Frestedt et al. evaluated the effects of $40 \mathrm{~g}$ of whey along with a weight-loss diet on body composition for 12 weeks; in this study, the whey-receiving group had the greater reduction in body fat and lower decrease in muscle mass compared to maltodextrin. Whey supplementation also led to $6.1 \%$ reduction in body fat mass, while a $5 \%$ reduction in body fat could reduce the risk of obesity-related diseases [37]. Also, in the present study, $7.14 \%$ reduction in body fat mass was observed in the whey protein group. Whey protein supplement can reduce body fat through hormones that affect the metabolism, such as reducing the uptake of the T3 hormone [38]. In contrast, Aldrich et al. rejected the hypothesis that a whey protein intervention along with weight-loss diet would result in greater weight loss and improve body composition compared to standard weight-loss diets, but significant differences in regional fat loss and in decreased blood pressure were observed in the whey protein group [39].

Differences in delivery methods (i.e., preload, as a stand-alone supplement, with a meal), varying doses and forms of whey protein (i.e., WPC, WPI, WPH), duration of trial, sample size, and the population under study yielded the contradictory results.

Despite roles of dairy proteins in modulating inflammation, oxidative stress, hypertension, risk factors of metabolic diseases, food intake behaviors, and other processes, no attention had been given to their effect on AEA, 2-AG, and other endocannabinoids. The ECs might also represent a key target for the treatment of abdominal obesity and associated metabolic changes. It seems that ECB is a key player in macronutrient metabolism between organs involved in food intake and systemic energy balance [17]. Among the strengths of the study was the use of a lower dose of whey protein, regular follow-up of subjects for observing diet, supplement intake and physical activity, and assessment of effect of whey protein on endocannabinoid levels for the first time. One of the limitations of this study was that $\mathrm{CB} 1$ and ECs metabolizing enzyme gene expression were not measured. Another limitation was using the ELISA kits instead HPLC to measure plasma endocannabinoids. Further researches are needed to determine the effect of whey protein on CB1 and ECs metabolizing enzyme gene expression and levels of other endocannabinoids.

\section{Conclusions}

The effects of simultaneous weight-loss diet and whey protein supplementation on the reduction of anandamide and 2-arachidonoylglyceride were demonstrated in this study. The other benefits of whey protein supplementation along with weight-loss diet on health were reported.

\section{Abbreviations \\ ECS: Endocannabinoid system; EC: Endocannabinoid; MD: Mean difference; Cl: Confidence interval; SFA: Saturated fatty acid; MUFA: Monounsaturated fatty acid; PUFA: Polyunsaturated fatty acid; IPAQ: International Physical Activity Questionnaire; BMI: Body mass index; WC: Waist circumference; AEA: Anandamide; 2-AG: 2-Arachidonoylglyceride; TC: Total cholesterol; LDL- C: Low-density lipoprotein cholesterol; HDL-C: High-density lipoprotein cholesterol; TG: Triglycerides; FBS: Fasting blood sugar; HOMA- \\ IR: Homeostasis model assessment for insulin resistance}

\section{Acknowledgements}

This paper was a part of degree PhD dissertation fulfilled by Vahideh Aghamohammadi. This study was financially supported by the Nutrition and Metabolic Disease Research Center of Ahvaz Jundishapur University of Medical Sciences (grant number: NRC-9513). We hereby express our gratitude to the study participants.

Authors' contributions

All the authors were involved in designing the study and drafting the protocol. All the authors also read and approved the final protocol.

\section{Funding}

This article was a part of degree PhD dissertation fulfilled by Vahideh Aghamohammadi. This study was financially supported by the Nutrition and Metabolic Disease Research Center of Ahvaz Jundishapur University of Medical Sciences (grant number: NRC-9513).

\section{Availability of data and materials}

The data could be available on request to the authors.

\section{Ethics approval and consent to participate}

This protocol, approved by the Medical Ethics Committee of Ahvaz Jundishapur University of Medical Sciences, was in accordance with the Declaration of Helsinki (approval number: IR.AJUMS.REC.1395.729). Each subject also signed an informed consent form. Moreover, this investigation was registered on the Iranian Registry of Clinical Trials (IRCT registration number: IRCT2017021410181N8)

Competing interests

The authors declared no competing interests. 


\section{Author details}

${ }^{1}$ Department of Nutrition, Nutrition and Metabolic Research Center, Faculty of Paramedical Sciences, Ahvaz Jundishapur University of Medical Sciences, Golestan Street, Ahvaz, Iran. ${ }^{2}$ Department of Nutrition, Khalkhal University of Medical Sciences, Khalkhal, Iran. ${ }^{3}$ Department of Statistics and Epidemiology, Faculty of Public Health, Ahvaz Jundishapur University of Medical Sciences, Ahvaz, Iran. ${ }^{4}$ Department of Statistics and Epidemiology, Faculty of Health, Tabriz University of Medical Sciences, Tabriz, Iran.

\section{Received: 28 September 2019 Accepted: 6 July 2020} Published online: 17 July 2020

\section{References}

1. Ng M, Fleming T, Robinson M, Thomson B, Graetz N, Margono C, Mullany EC, Biryukov S, Abbafati C, Abera SF. Global, regional, and national prevalence of overweight and obesity in children and adults during 19802013: a systematic analysis for the Global Burden of Disease Study 2013. Lancet. 2014;384:766-81.

2. Rahmani A, Sayehmiri K, Asadollahi K, Sarokhani D, Islami F, Sarokhani M. Investigation of the prevalence of obesity in Iran: a systematic review and meta-analysis study. Acta Medica Iranica. 2015;53(10):596-607.

3. Ayatollahi S, Ghoreshizadeh Z. Prevalence of obesity and overweight among adults in Iran. Obes Rev. 2010;11:335-7.

4. Bischoff SC, Boirie Y, Cederholm T, Chourdakis M, Cuerda C, Delzenne NM, Deutz NE, Fouque D, Genton L, Gil C. Towards a multidisciplinary approach to understand and manage obesity and related diseases. Clin Nutr. 2017;36: 917-38.

5. Knight JA. Diseases and disorders associated with excess body weight. Ann Clin Lab Sci. 2011;41:107-21.

6. Watkins BA, Kim J. The endocannabinoid system: directing eating behavior and macronutrient metabolism. Front Psychol. 2015;5:1506.

7. Bennetzen MF, Wellner N, Ahmed SS, Ahmed S, Diep TA, Hansen HS, Richelsen B, Pedersen S. Investigations of the human endocannabinoid system in two subcutaneous adipose tissue depots in lean subjects and in obese subjects before and after weight loss. Int J Obes. 2011;35:1377-84.

8. Silvestri C, Di Marzo V. The endocannabinoid system in energy homeostasis and the etiopathology of metabolic disorders. Cell Metab. 2013;17:475-90.

9. Jones PJ, Lin L, Gillingham LG, Yang H, Omar JM. Modulation of plasma Nacylethanolamine levels and physiological parameters by dietary fatty acid composition in humans. J Lipid Res. 2014;55:2655-64.

10. Fanelli F, Di Lallo VD, Belluomo I, De lasio R, Baccini M, Casadio E, Gasparini DI, Colavita M, Gambineri A, Grossi G. Estimation of reference intervals of five endocannabinoids and endocannabinoid related compounds in human plasma by two dimensional-LC/MS/MS. J Lipid Res. 2012;53:481-93.

11. Blüher M, Engeli S, Klöting N, Berndt J, Fasshauer M, Bátkai S, Pacher P, Schön MR, Jordan J, Stumvoll M. Dysregulation of the peripheral and adipose tissue endocannabinoid system in human abdominal obesity. Diabetes. 2006;55:3053-60.

12. Sipe JC, Scott TM, Murray S, Harismendy O, Simon GM, Cravatt BF, Waalen J. Biomarkers of endocannabinoid system activation in severe obesity. PLoS One. 2010;5(1):e8792.

13. Sukkar SG, Vaccaro A, Ravera GB, Borrini C, Gradaschi R, Massa SacchiNemours A, Cordera R, Andraghetti G. Appetite control and gastrointestinal hormonal behavior (CCK, GLP-1, PYY 1-36) following low doses of a whey protein-rich nutraceutic. Mediterr J Nutr Metab. 2013;6:259-66.

14. Sousa GT, Lira FS, Rosa JC, de Oliveira EP, Oyama LM, Santos RV, Pimentel $\mathrm{GD}$. Dietary whey protein lessens several risk factors for metabolic diseases: a review. Lipids Health Dis. 2012;11:67.

15. Diaz S, Farhang B, Hoien J, Stahlman M, Adatia N, Cox JM, Wagner EJ. Sex differences in the cannabinoid modulation of appetite, body temperature and neurotransmission at POMC synapses. Neuroendocrinology. 2009;89: 424-40.

16. Mitchell VA, Jeong H-J, Drew GM, Vaughan CW. Cholecystokinin exerts an effect via the endocannabinoid system to inhibit GABAergic transmission in midbrain periaqueductal gray. Neuropsychopharmacology. 2011;36:1801-10.

17. Haidari F, Aghamohammadi V, Mohammadshahi M, Ahmadi-Angali K. Effect of whey protein supplementation on levels of endocannabinoids and some of metabolic risk factors in obese women on a weight-loss diet: a study protocol for a randomized controlled trial. Nutr J. 2017;16:70.

18. Mallipedhi A, Prior S, Dunseath G, Bracken R, Barry J, Caplin S, Eyre N, Morgan J, Baxter J, O'Sullivan S. Changes in plasma levels of EAE and PEA following bariatric surgery in morbidly obese females with impaired glucose homeostasis. J Diabetes Res. 2015;680867.

19. Craig C, Marshall A, Sjostrom M, Bauman A, Lee P, Macfarlane D, Lam T, Stewart S. International Physical Activity Questionnaire-Short Form; 2017.

20. Mifflin MD, St Jeor ST, Hill LA, Scott BJ, Daugherty SA, Koh YO. A new predictive equation for resting energy expenditure in healthy individuals. Am J Clin Nutr. 1990;51:241-7.

21. O'Hare JD, Zieliński E, Cheng B, Scherer T, Buettner C. Central endocannabinoid signaling regulates hepatic glucose production and systemic lipolysis. Diabetes. 2011;60:1055-62.

22. Engeli S, Heusser K, Janke J, Gorzelniak K, Bátkai S, Pacher P, Harvey-White J, Luft FC, Jordan J. Peripheral endocannabinoid system activity in patients treated with sibutramine. Obesity. 2008;16:1135-7.

23. Di Marzo V, Cote M, Matias I, Lemieux I, Arsenault B, Cartier A, Piscitelli F, Petrosino S, Almeras N, Després J-P. Changes in plasma endocannabinoid levels in viscerally obese men following a 1 year lifestyle modification programme and waist circumference reduction: associations with changes in metabolic risk factors. Diabetologia. 2009;52:213.

24. Adams RL, Broughton KS. Insulinotropic effects of whey: mechanisms of action, recent clinical trials, and clinical applications. Ann Nutr Metab. 2016; 69:56-63.

25. Frid AH, Nilsson M, Holst JJ, Björck IM. Effect of whey on blood glucose and insulin responses to composite breakfast and lunch meals in type 2 diabetic subjects. Am J Clin Nutr. 2005;82:69-75.

26. Wu T, Little TJ, Bound MJ, Borg M, Zhang X, Deacon CF, Horowitz M, Jones $\mathrm{KL}$, Rayner CK. A protein preload enhances the glucose-lowering efficacy of vildagliptin in type 2 diabetes. Diabetes Care. 2016;39:511-7.

27. Sukkar S, Signori A, Borrini C, Barisione G, Ivaldi C, Romeo C, Gradaschi R, Machello N, Nanetti E, Vaccaro A. Feasibility of protein-sparing modified fast by tube (ProMoFasT) in obesity treatment: a phase II pilot trial on clinical safety and efficacy (appetite control, body composition, muscular strength, metabolic pattern, pulmonary function test). Mediterr J Nutr Metab. 2013;6: 165-76.

28. Piccolo BD, Comerford KB, Karakas SE, Knotts TA, Fiehn O, Adams SH. Whey protein supplementation does not alter plasma branched-chained amino acid profiles but results in unique metabolomics patterns in obese women enrolled in an 8-week weight loss trial. J Nutr. 2015;145:691-700.

29. Almario RU, Buchan WM, Rocke DM, Karakas SE. Glucose-lowering effect of whey protein depends upon clinical characteristics of patients with type 2 diabetes. BMJ Open Diabetes Res Care. 2017;5:e000420.

30. Bendtsen LQ, Lorenzen JK, Bendsen NT, Rasmussen C, Astrup A. Effect of dairy proteins on appetite, energy expenditure, body weight, and composition: a review of the evidence from controlled clinical trials. Adv Nutr. 2013;4:418-38.

31. Graf S, Egert S, Heer M. Effects of whey protein supplements on metabolism: evidence from human intervention studies. Curr Opin Clin Nutr Metab Care. 2011;14:569-80.

32. Pal $S$, Ellis $V$, Dhaliwal $S$. Effects of whey protein isolate on body composition, lipids, insulin and glucose in overweight and obese individuals. Br J Nutr. 2010;104:716-23.

33. Hong S-M, Chung E-C, Kim C-H. Anti-obesity effect of fermented whey beverage using lactic acid bacteria in diet-induced obese rats. Korean J Food Sci Anim Resour. 2015;35:653.

34. Sukkar SG, Cella F, Patriarca S, Furfaro AL, Abate F, Ferrari C, Balbis E, Traverso N, Cottalasso D. Whey protein, as exclusively nitrogen source, controls food intake and promotes glutathione antioxidant protection in Sprague-Dawley rats. Mediterr J Nutr Metab. 2008;1:109-16.

35. Hall W, Millward D, Long S, Morgan L. Casein and whey exert different effects on plasma amino acid profiles, gastrointestinal hormone secretion and appetite. Br J Nutr. 2003;89:239-48.

36. Soop M, Nehra V, Henderson GC, Boirie Y, Ford GC, Nair KS. Coingestion of whey protein and casein in a mixed meal: demonstration of a more sustained anabolic effect of casein. Am J Physiol Endocrinol Metab. 2012; 303:E152-62.

37. Frestedt JL, Zenk JL, Kuskowski MA, Ward LS, Bastian ED. A whey-protein supplement increases fat loss and spares lean muscle in obese subjects: a randomized human clinical study. Nutr Metab. 2008;5:8.

38. Baer DJ, Stote KS, Paul DR, Harris GK, Rumpler W, Clevidence BA. Whey protein but not soy protein supplementation alters body weight and composition in free-living overweight and obese adults. J Nutr. 2011;141: 1489-94. 
39. Aldrich ND, Reicks MM, Sibley SD, Redmon JB, Thomas W, Raatz SK. Varying protein source and quantity do not significantly improve weight loss, fat loss, or satiety in reduced energy diets among midlife adults. Nutr Res. 2011;31:104-12

\section{Publisher's Note}

Springer Nature remains neutral with regard to jurisdictional claims in published maps and institutional affiliations.

Ready to submit your research? Choose BMC and benefit from:

- fast, convenient online submission

- thorough peer review by experienced researchers in your field

- rapid publication on acceptance

- support for research data, including large and complex data types

- gold Open Access which fosters wider collaboration and increased citations

- maximum visibility for your research: over $100 \mathrm{M}$ website views per year

At $B M C$, research is always in progress.

Learn more biomedcentral.com/submissions 